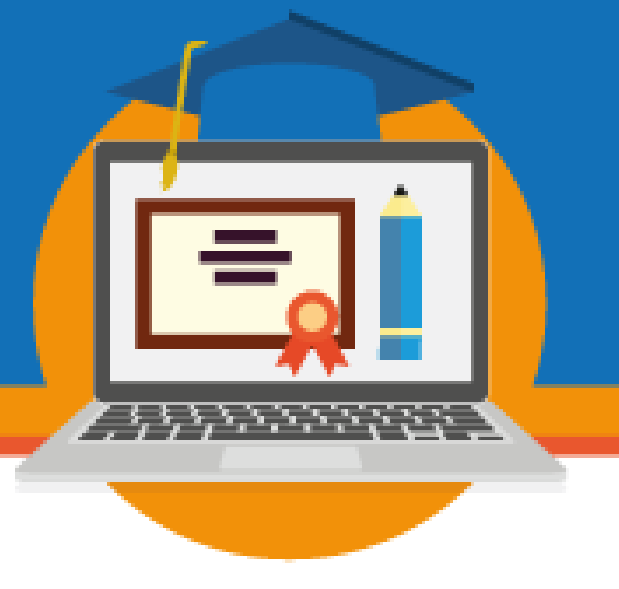

\title{
A GAMIFICAÇÃO NA EDUCAÇÃO SUPERIOR A DISTÂNCIA: O PROGRAMA DESAFIO NOTA MÁXIMA
}

\author{
Eduardo Henrique Oliveira da Silva \\ Núcleo de Tecnologia Educacional- Brasil \\ e-mail: edhenriqueh@hotmail.com
}

\begin{abstract}
Resumo: Este texto constitui em um relato de experiência acadêmica do autor como estudante de graduação do curso de Pedagogia. O objetivo geral foi: analisar o Programa Desafio Nota Máxima, no processo de aprendizagem dos alunos de graduação licenciatura em Pedagogia de educação superior a distância. Os objetivos específicos são: a) caracterizar uma plataforma digital gamificada na educação superior a distância e o Programa Desafio Nota Máxima; b) identificar e examinar os elementos de gamificação incorporados naquele programa. Este relato insere-se na abordagem qualitativa, sob a perspectiva descritiva e explicativa. Concluiu-se que o Programa Desafio Nota Máxima proporcionou ao estudante a ação, apropriação e [re] construção dos conhecimentos adquiridos durante aquele curso de graduação.
\end{abstract}

Palavras-chave: Educação superior a distância; Gamificação; Plataformas gamificadas.

\section{Introdução}

Os jogos, jogos eletrônicos, games/videogames, gamers (jogadores), designer (criador) de jogos, consoles ${ }^{1}$, ambientes e plataformas gamificadas ${ }^{2}$, estéticas, estratégias ou mecânicas de jogos, compõem o léxico que designam pessoas e instituições que utilizam aqueles jogos ou seus elementos nos diversos aspectos da vida material: trabalho, escola, lazer, entre outros.

Assim, na contemporaneidade, os games ou videogames, impulsionados pela indústria de entretenimento, emergiram dos momentos de divertimento e de lazer, e têm sido utilizados

\footnotetext{
${ }^{1}$ Console é definido como um terminal utilizado em computador ou videogame que permite ao operador intervir no controle da máquina ou no processamento efetuado por ela (BORBA, 2011, p. 329).

${ }^{2}$ É um termo oriundo do Inglês, gamification, mas, em Português têm sido grafados como gameficação, ora gamificação, ambos conservam o prefixo game que quer dizer jogo(s). Por derivação constitui um neologismo que tem servido para designar os processos educativos ou de desenvolvimento profissional que utilizam as mecânicas de jogos em diversas áreas do conhecimento.
} 


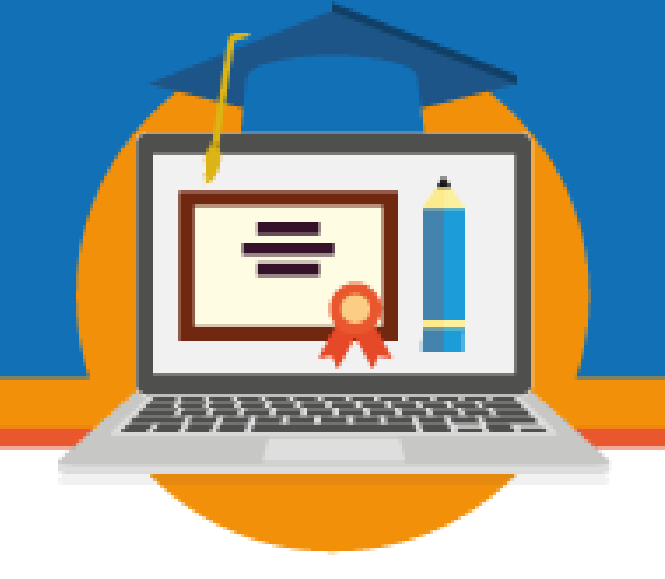

por empresas para treinamento de funcionários, e na educação, como estratégia e/ou metodologia de ensino e de aprendizagem, sobretudo, na educação superior a distância que constitui o recorte temático deste trabalho.

Desse modo, este texto é um relato de experiência acadêmica do autor como estudante de graduação em Pedagogia, licenciatura, na modalidade de educação superior a distância (EaD) em uma instituição de ensino particular, no município de Corumbá, estado de Mato Grosso do Sul (MS), no período de 2014 a 2017.

Teve como objetivo geral: analisar o Programa Desafio Nota Máxima, suportado pela plataforma digital gamificada Studiare, no processo de aprendizagem dos alunos de graduação, licenciatura em Pedagogia de educação superior a distância, no período delimitado.

Os objetivos específicos consistiram em: a) caracterizar uma plataforma digital gamificada na educação superior a distância e o Programa Desafio Nota Máxima; b) identificar e examinar os elementos de gamificação incorporados naquele programa por meio da plataforma digital Studiare.

Para os fins deste trabalho, o texto está estruturado em três seções, além da introdução, considerações finais e referências. Na primeira parte, apresenta a fundamentação teórica acerca do objeto relatado. Na sequência, descreve-se o percurso metodológico adotado neste trabalho. Por fim, expõe-se a análise crítica da utilização da gamificação no processo de aprendizagem dos conteúdos estudados durante o curso de graduação em Pedagogia por meio da EaD.

$\mathrm{Na}$ próxima seção, apresenta-se a fundamentação teórica concernente ao tema em estudo, bem como a interlocução, análise e interpretação dos dados com vistas a produção do conhecimento científico acerca do objeto estudado.

\section{Fundamentação teórica: os games e as plataformas digitais gamificadas como objetos de estudos na educação superior a distância}

Os games, desde meados da década de 1970, estão presentes na sociedade contemporânea proporcionando diversão/lazer às pessoas, "movimentando em 2007, uma cifra de U\$ 41 milhões de dólares no mundo, superando a indústria do cinema, gerando a abertura 
de empresas na área de desenvolvimento de games" [...] (ALVES, 2009, p. 375), se tornando a "terceira em faturamento do mundo, sendo superada pelas indústrias bélica e automobilística" (ALVES, 2013, p. 178).

O alcance dos games nos diversos aspectos da vida em sociedade pode ser constatado em reportagens jornalísticas como: i) "O mercado de games no mundo fatura mais que cinema e música, somados” (VIDOR, 2015); ii) "Empresas usam jogos e representação de papéis para treinar os líderes" (GUTIERREZ, 2015); iii) "Games na educação brasileira: solução de problemas ou ferramenta de aprendizado" (UNIVERSIA, 2014).

Visando comprovar tais afirmações, realizou-se um levantamento bibliográfico concernente a utilização de games na educação, sobretudo, na educação superior a distância, e foi possível compreender que os termos games, videogames, videojogos são utilizados como sinônimos para referir-se aos jogos comerciais, jogados em consoles (Sony Playstation; Microsoft XBox) e computador pessoal (SILVA; MOITA, 2006), que integram a terceira e quarta gerações de jogos (ALVES, 2008), possibilitando uma alternativa de entretenimento e de lazer que atende as diversas faixas etárias (FARDO, 2013). Desse modo,

Os games se tornaram uma forma significativa de entretenimento e assumiram um relevante papel sociocultural na vida das crianças e jovens e por isso são capazes de fomentar a construção do aprendizado para a cidadania de forma lúdica e contextualizada com a realidade na qual estão inseridos (TORRES; ALVES, 2013, p. 175, grifo nosso).

Como se vê, os games estão presentes na vida das pessoas, proporcionando aos usuários momentos de diversão, lazer, aprendizado dos saberes e dos conteúdos sociais produzidos e difundidos na sociedade. Em vista disso, há um movimento de propor a utilização de games nos currículos escolares porque "contempla-se a possibilidade de interação, criação, cooperação e novas formas de comunicar e com processos colaborativos contribuir para a construção de novas aprendizagens" (SILVA; MOITA, 2006, p. 2).

Dessa maneira, possibilita unir a seriedade do ensino ao prazer gerado pelos jogos, favorecendo o processo de aprendizagem mais significativo e motivador aos alunos na busca pela construção do conhecimento, portanto, "os games como agentes motivadores na educação" (NOGUEIRA; GALDINO, 2011, p. 1).

\section{SEMINÁRIO DE EDUCAÇÃO A DISTÂNCIA}




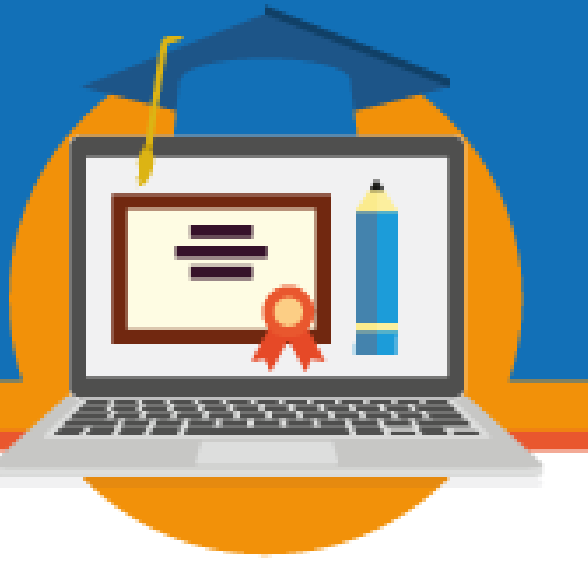

A introdução dos games, nos processos de ensino e de aprendizagem, fez surgir o termo gamificação que consiste em utilizar os elementos de games como as dinâmicas, estratégias, estéticas, lógica, mecânicas ou pensamento, fora do contexto dos jogos com o propósito de engajar, motivar e mediar os processos de aprendizagem ou de desenvolvimento profissional que utilizam aqueles elementos na resolução de situações-problema nas diversas atividades do dia a dia (FARDO, 2013).

Diante disso, a gamificação é um termo que contém os elementos utilizados em jogos compostos de desafios, estratégias, obtenção de pontos, feedback imediatos, recompensas (medalhas e prêmios) ou ranking (FRANÇA; REATEGUI; COLLARES, 2014), quando o jogador alcança os objetivos determinados pelos planos de estudos e das tarefas, tornando as atividades mais atraentes para aqueles envolvidos nos processos de escolarização (desde a educação infantil a educação superior) ou de desenvolvimento profissional do mundo do trabalho.

Desse modo, compreende-se que "a gamificação não é um jogo (ou processo para se transformar algo em jogo), mas sim a utilização de abstrações e metáforas originárias da cultura e estudos de videogames em áreas não relacionadas a videogames" (ALVES; MACIEL, 2014, p. 4), como por exemplo, empresarial, marketing, propaganda, e agora no campo educacional.

A utilização da gamificação na educação tem se materializado pela modalidade de $\mathrm{EaD}^{3}$ por intermédio das plataformas digitais que são infraestruturas tecnológicas (BEHAR, 2007; 2009) que viabilizam a criação de programas educacionais e/ou formativos nas diversas áreas do conhecimento (KEEGAN, 2002), concretizados nos ambientes virtuais de aprendizagem (AVA) que são:

[...] sistemas computacionais disponíveis na internet, destinados ao suporte de atividades mediadas pelas tecnologias de informação e comunicação. Permitem integrar múltiplas mídias, linguagens e recursos, apresentar informações de maneira organizada, desenvolver interações entre pessoas e objetos de conhecimento, elaborar e socializar produções tendo em vista atingir determinados objetivos (ALMEIDA, 2003, p. 331).

${ }^{3}$ Institucionalizada pela Lei $\mathrm{n}^{\circ}$ 9.394, de 20 de dezembro de 1996, conforme o Art. 80 (BRASIL, 1996). Regulamentada e definida pelo Decreto $\mathrm{n}^{\circ} 5.622$, de 19 de dezembro de 2005 (BRASIL, 2005), e posteriormente, revogado pelo Decreto $n^{\circ}$ 9.057, de 25 de maio de 2017 (BRASIL, 2017).

\section{SEMINÁRIO DE EDUCAÇÃO A DISTÂNCIA}




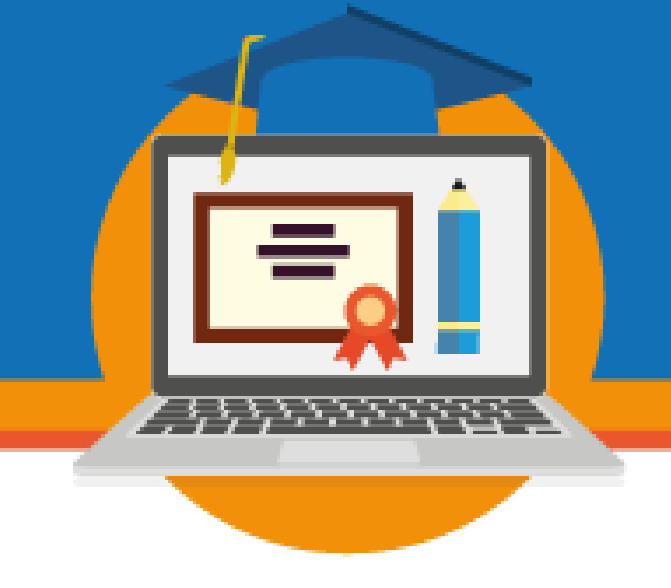

Depreende-se que é o AVA que dá materialidade às plataformas digitais gamificadas porque permite a inserção das dinâmicas/elementos/estéticas/mecânicas de games/jogos nos processos de ensino e de aprendizagem dos estudantes de graduação superior na modalidade de EaD, aqui, representado pelo Programa Desafio Nota Máxima (PDNM), concebido, planejado, desenvolvido, avaliado e disponibilizado pela plataforma digital Studiare, termo oriundo do idioma italiano que significa estudo(s).

Dessa maneira, o estudante poderá complementar seus estudos com a participação no PDNM com vistas a superar as lacunas de aprendizagem durante o processo de formação inicial no curso de graduação superior em Pedagogia, na modalidade de EaD, considerando que a plataforma digital gamificada, oportuniza planos de estudos individualizados, revisa e avalia os conteúdos estudados em sala de aula, feedback (respostas) imediatas da realização das tarefas, visando melhorar o desempenho acadêmico (PROGRAMA DESAFIO NOTA MÁXIMA, 2014).

Pimenta e Almeida (2013) evidenciaram que a inserção da gamificação em AVA, tornam-se os processos de ensino mais atrativos porque possibilita ao estudante a exploração, experimentação, interação, colaboração, autonomia, autoria e consciência sobre o processo de aprendizagem, portanto, a gamificação se constitui em recurso didático a ser utilizado nos AVA.

De modo análogo, Schlemmer (2014) salientou que a incorporação da gamificação nos AVA tem proporcionado ao estudante duas dimensões educativo-formativas, quais sejam: a) de persuasão; e, b) de construção. A persuasão consiste em realizar e ser premiado pelas tarefas desenvolvidas; enquanto, a construção está relacionada com a resolução de problemas e engajamento dos sujeitos nas tarefas de aprendizagens porque o indivíduo aprende ressignificando as informações e conhecimentos na relação dialética jogo/jogador.

Por outro lado, Mattar e Nesteriuk (2016, p. 7), advertiram que o conceito de gamificação não deve ser "associado à ideia de premiação como forma de motivação", pois assim fazendo, reforça um comportamento baseado no estímulo-resposta (behaviorismo), tornando os processos de ensino e de aprendizagem reducionistas, uma vez que vincula a 


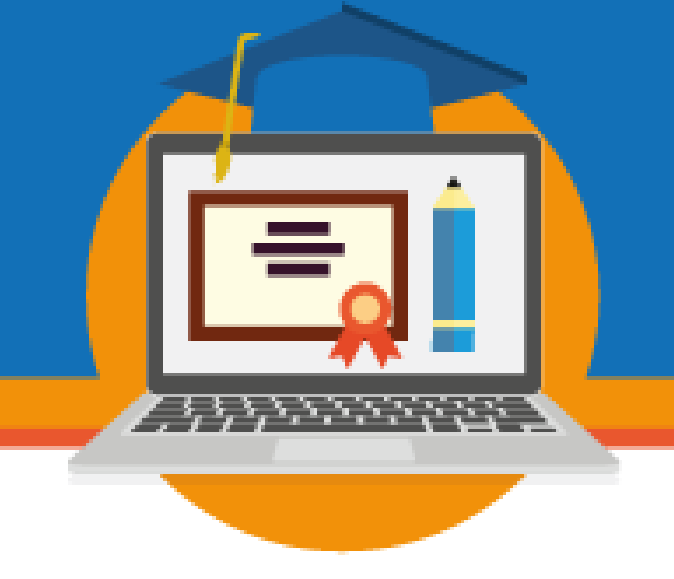

motivação dos alunos aos prêmios ou notas, desconsiderando a ação, reflexão-mediada e sínteses, realizados acerca dos objetos estudados.

Em suma, Schlemmer (2016) destacou que os games e a gamificação se impõem como alternativas metodológicas aos modelos de EaD por propiciar ao estudante o engajamento no processo de aprendizagem durante sua formação inicial nos cursos de graduação superior naquela modalidade de ensino.

Portanto, a fundamentação teórica permitiu constatar as produções científicas acerca do objeto, possibilitando construir um referencial teórico, e a justificativa da realização do estudo ora relatado. $\mathrm{Na}$ próxima seção será descrita o percurso metodológico que propiciou a reconstrução de novos conhecimentos, representações conceituais, concernentes ao objeto estudado.

\section{Metodologia}

Este relato de experiência é de cunho teórico, com a abordagem qualitativa, sob a perspectiva descritiva e explicativa que teve a pesquisa bibliográfica e documental como fonte de levantamento de dados concernentes aos temas educação a distância, games e gamificação. As produções científicas encontradas foram lidas, fichadas, transcritas de forma direta e indireta com o propósito de construir uma interlocução teórica com os autores, com vistas a produção do conhecimento científico do objeto relatado.

Os sujeitos deste relato são 49 (quarenta e nove) estudantes que ingressaram em 2014 e concluíram em 2017, o curso de Pedagogia, licenciatura, oferecido por uma Instituição de Educação Superior (IES), na modalidade de EaD, no município de Corumbá, estado de Mato Grosso do Sul. O curso de Pedagogia é composto de 8 (oito) semestres com duração de 4 (quatro) anos letivos, contemplando as disciplinas e programas de estudos obrigatórios à formação de profissionais para atuarem em instituições escolares e não escolares.

Os procedimentos metodológicos tiveram como base empírica: a) o acesso na plataforma digital gamificada, Studiare, pela qual o PDNM tornou-se viável; b) manejo das 


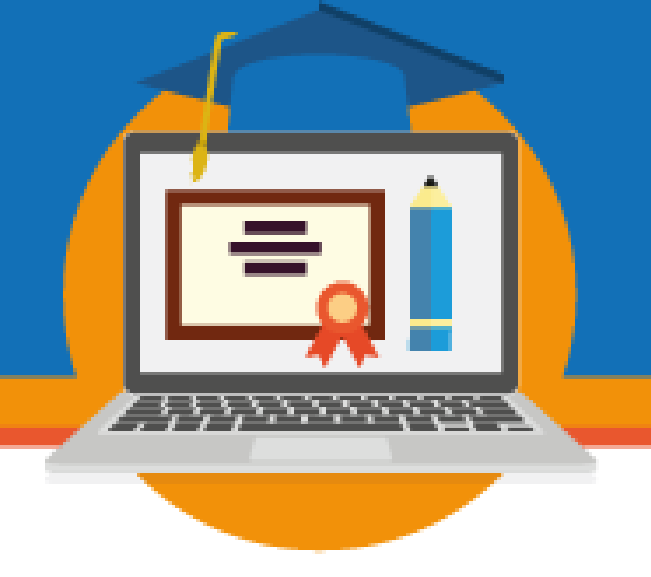

interfaces ${ }^{4}$ dos conteúdos e das atividades do PDNM a serem realizadas na/pela referida plataforma, por meio do simulado diagnóstico e das listas de tarefas semanal contendo 4 (quatro) questões, pontuadas durante o período de estudos.

Assim, os dados coletados são oriundos do acesso e do manejo das interfaces disponibilizadas por aquela plataforma que foram organizados sob a forma de figuras ilustrativas e de textos analíticos. Os resultados obtidos foram interpretados mediante a interlocução teórica com os autores mobilizados na fundamentação teórica deste trabalho.

\section{Resultados e discussão: análise crítica da gamificação presente no Programa Desafio Nota Máxima como mediação do processo de aprendizagem do curso de Pedagogia a distância}

Inicialmente, em 2014, o PDNM era um tópico complementar de estudos que integrava o rol de atividades e de tarefas, juntamente com outras disciplinas estudadas no curso de graduação, licenciatura em Pedagogia. Entretanto, a partir do segundo semestre do ano de 2016, o PDNM foi vinculado como atividade obrigatória do componente curricular Seminário Interdisciplinar.

O acesso ao PDNM é viabilizado pela plataforma digital gamificada, Studiare, na qual o estudante foi registrado com o cadastro de pessoa física (CPF) que gerou uma identificação de usuário (login) e senha, autorizando o estudante a participar do Programa, conforme a Figura 1.

Figura 1: Interface de acesso ao Programa Desafio Nota Máxima.

\footnotetext{
${ }^{4}$ Interface é um termo que na informática e na cibercultura ganha o sentido de dispositivo para encontro de duas ou mais faces em atitude comunicacional, dialógica ou polifônica. A Internet comporta diversas interfaces. Cada interface reúne um conjunto de elementos de hardware e software destinados a possibilitar aos internautas trocas, interações, agregações, associações e significações como autoria e co-autoria (SILVA; CLARO, 2007, p. 86).
} 

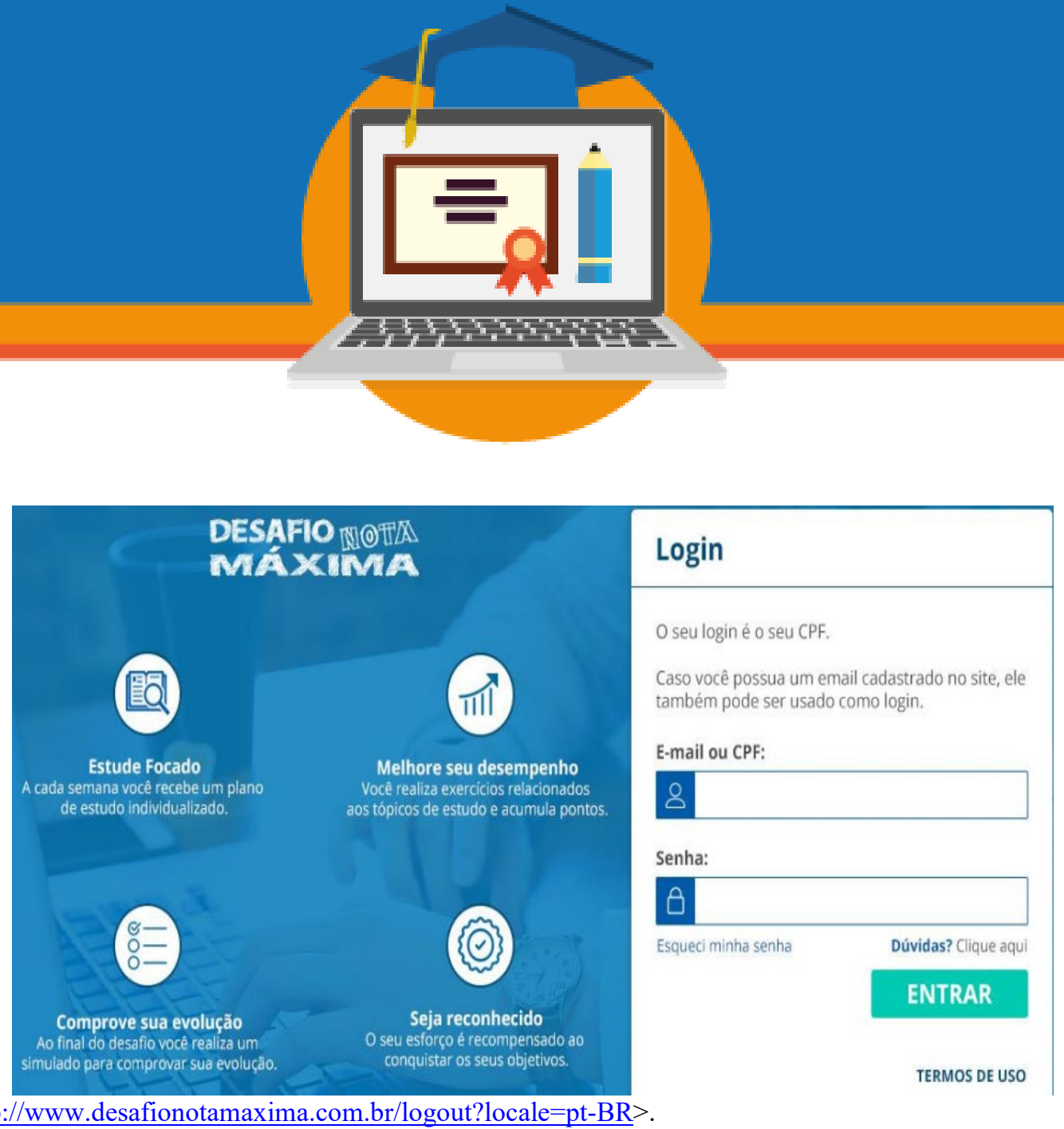

Fonte: $<$ http://www.desafionotamaxima.com.br/logout?locale=pt-BR $>$.

Após a inserção correta dos dados de login e senha (Figura 1), a plataforma digital gamificada Studiare, direciona o estudante para a interface Home de Estudos que apresenta uma visão completa do PDNM, contendo a identificação nominal, ano e período acadêmico (semestre), estudo personalizado, cronograma de estudo a ser realizado semanalmente, insígnias e os pontos acumulados com a realização das atividades e das tarefas, de acordo com a Figura 2.

Além disso, é mediante a interface Home de Estudos que o aluno teve a liçenca às outras como: a) Meu Desempenho (composta por meu desempenho; minhas insígnias; desempenho da turma); b) Informações (guia do aluno; pontos e notas; regulamento e vídeo PDNM). Como se vê, é a partir da interface Home de Estudos que o estudante tem acesso aos conteúdos, planos de estudos, etapas e tempo para realização, respostas imediatas de todas as atividades e tarefas propostas pelo PDNM (Figura 2).

Figura 2: Interfaces: Home de estudo, Mapa do aluno e Cronograma de estudos. 


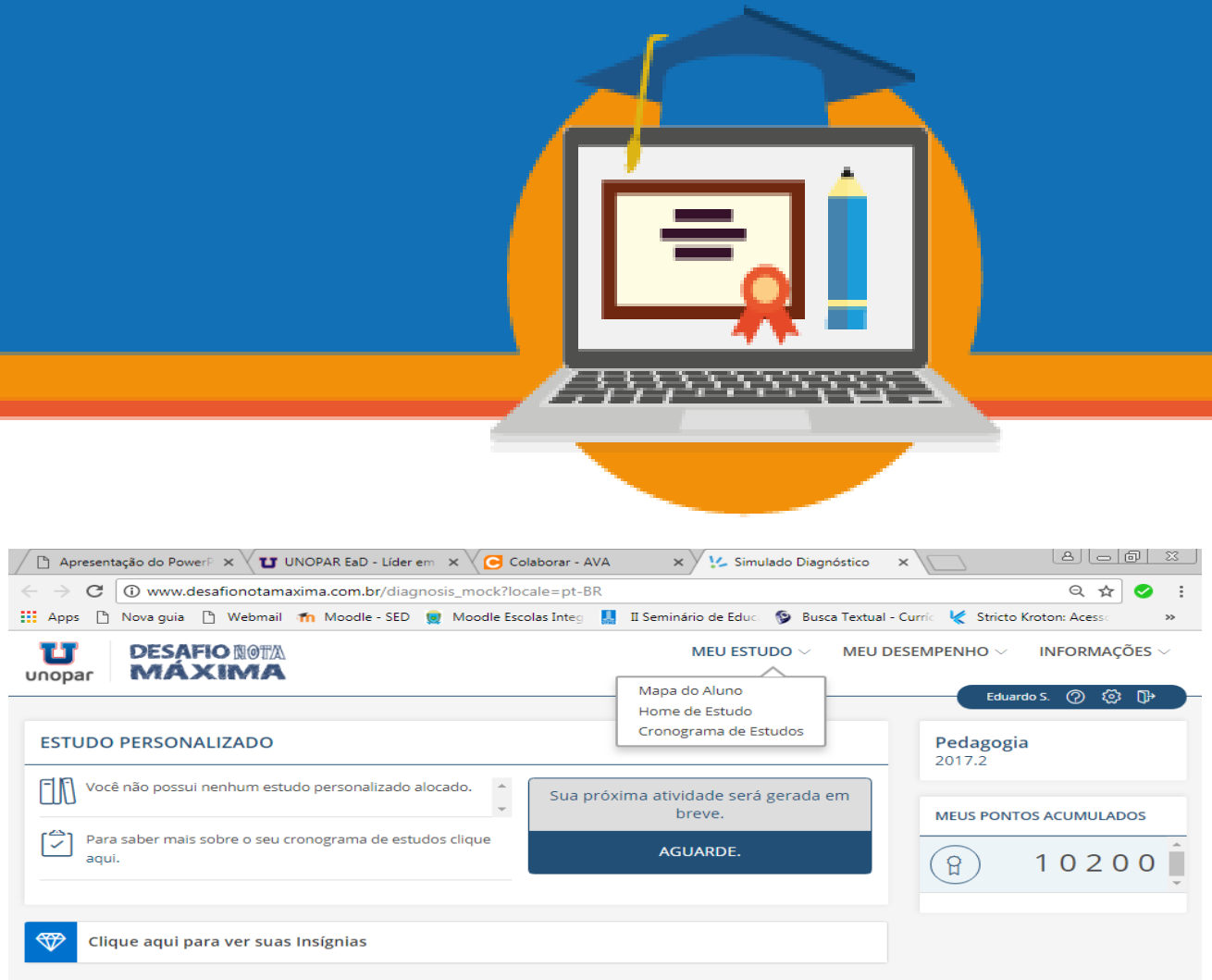

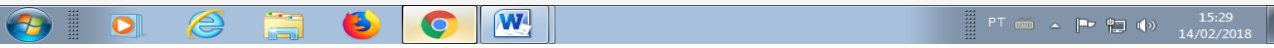

Fonte: $<$ http://www.desafionotamaxima.com.br/diagnosis mock?locale=pt-BR $>$.

A interface Mapa do Aluno permitiu o contato com os desafios, missões, atividades dos planos de estudos, questões bônus, simulados (instrumento que identifica as lacunas de aprendizagem do aluno) e itinerários de estudos, articulados aos conteúdos e temas abordados durante o curso, bem como oferece o posicionamento (ranking) dos estudantes enquanto realizam as tarefas propostas pelo PDNM, expressos pela Figura 3.

Figura 3: Interface mapa do aluno.

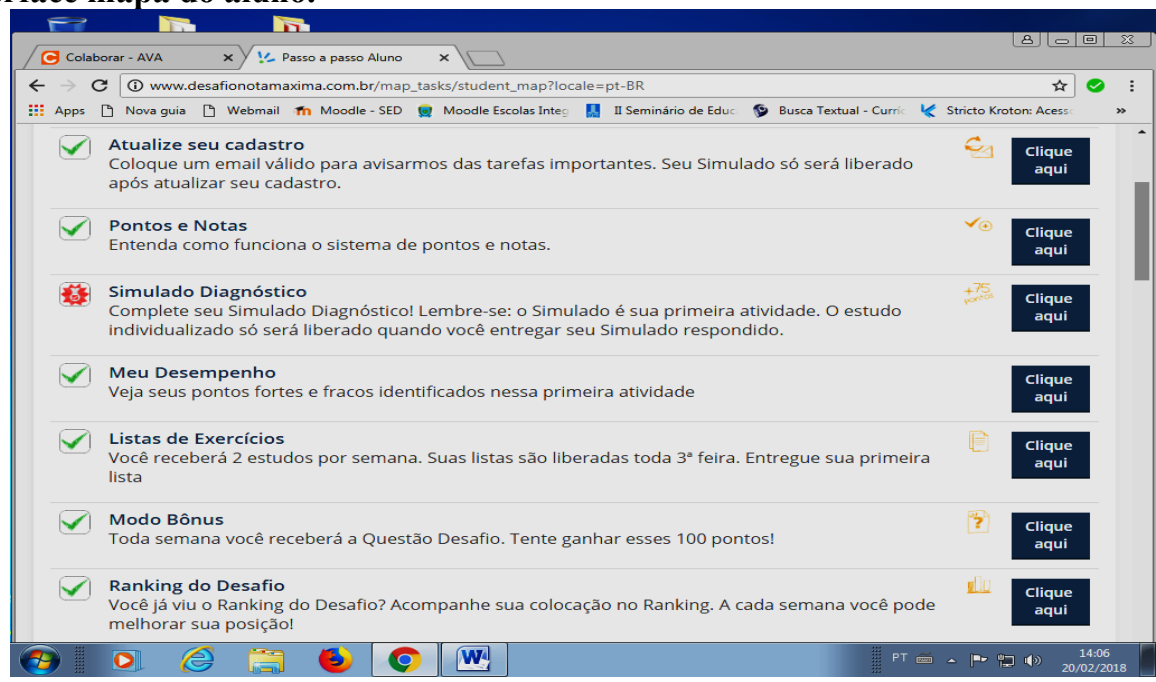

Fonte: $<$ http://www.desafionotamaxima.com.br/map tasks/student map $>$.

\section{SEMINÁRIO DE EDUCAÇÃO A DISTÂNCIA}

EaD na região Centro-Oeste: Institucionalização, Limites e Potencialidades

12 a 14 de abril de 2018 - Campo Grande/MS 
O estudante, após realizar as atividades e as tarefas, obtinha o resultado imediato, evidenciado pelos números porcentuais de acertos e de erros, assim como as pontuações correspondentes as questões acumuladas ao longo do processo de estudos, ocasionando o desempenho (performance) individual do aluno em relação aos demais participantes do programa, por área do conhecimento [(i) Específicas para gestão escolar e outros espaços educativos; ii) Formação geral: Ciências Humanas e Aplicadas; iii) Específicas para docência; Formação geral; iv) Formação geral pedagógica; v) Formação geral de educação superior], e por conteúdos, consoante Figura 4.

Figura 4: Interface de desempenho do aluno no PDNM.

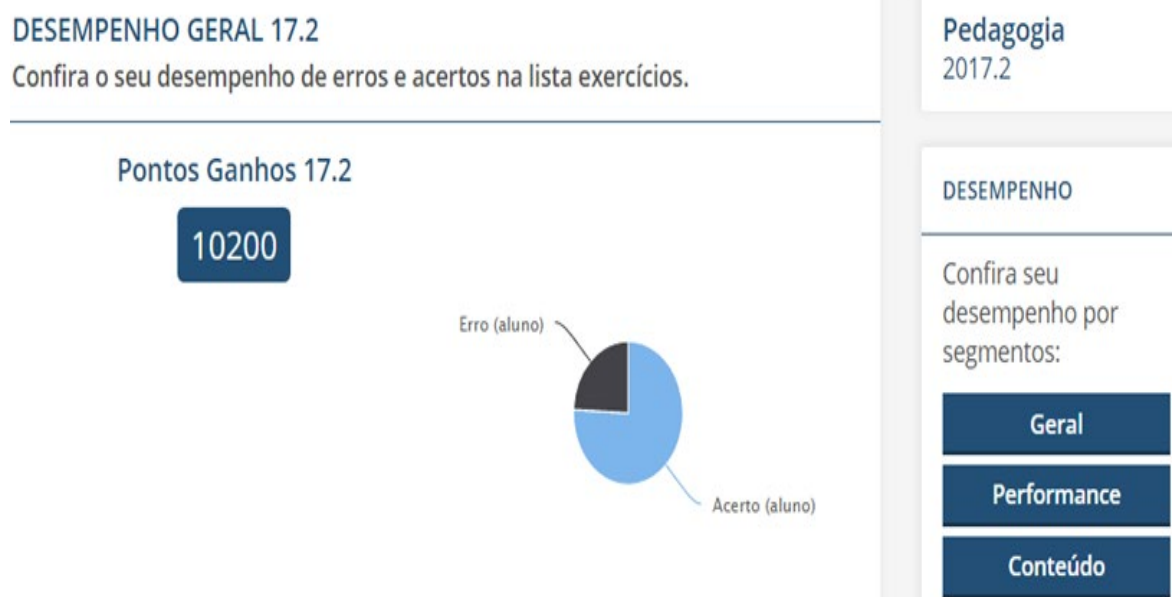

Fonte: $<$ http://www.desafionotamaxima.com.br/users/cumulative_performance $>$.

Assim, a realização de lista de exercícios, questões desafios, simulados e das tarefas eram recompensados pelo sistema de pontuação que variava de 449 pontos até acima de 9.000. Por conseguinte, aqueles pontos eram convertidos em uma escala de notas, de 0 (zero) a 10 (dez), cujas atribuições conceituais eram expressas por: alunos sem conceito ( 0 a 499 pontos, correspondem a nota zero), insuficiente (500 a 4999 pontos, correspondem as notas de 1 a 5), suficiente (5000 a 5999 pontos, correspondem a nota 6), bom (6000 a 6900 pontos, correspondem a nota 7), muito bom (7000 a 7999 pontos, correspondem a nota oito), excelente (8000 acima de 9000 pontos, correspondem as notas 9 e 10), em conformidade com a Figura 5. 


\section{$\Longrightarrow$

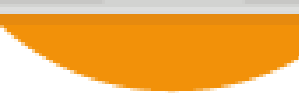

Figura 5: Interface de acesso ao sistema de pontos.

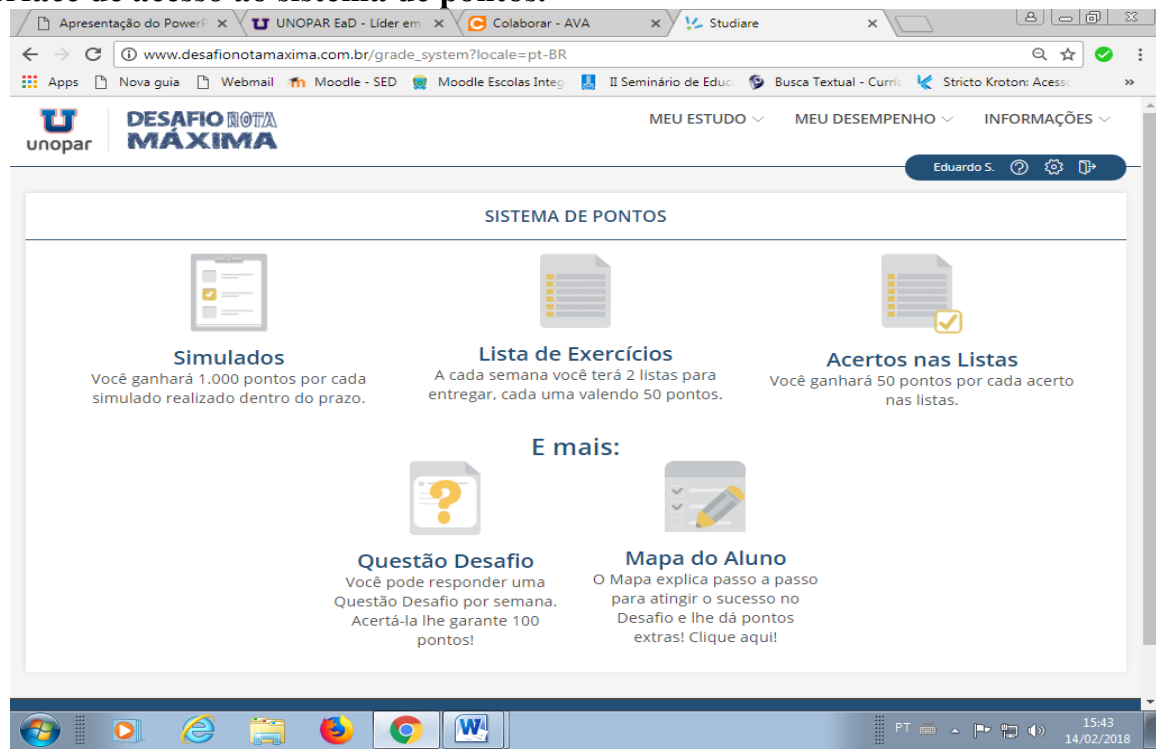

Fonte: $<$ http: $/ /$ www.desafionotamaxima.com.br/grade system?locale=pt-BR $>$.

Por intermédio das Figuras 1, 2, 3, 4 e 5 foi possível evidenciar as interfaces do PDNM que contém os elementos da gamificação, quais sejam: objetivos da aprendizagem, planos de estudos, missões, regras, emblemas e mecânicas de jogos, expressas pela obtenção de pontos, notas, recompensas, reconhecimentos, prestígio, insígnias, competição e desempenho alcançado pelas tarefas realizadas.

Disso resulta que a utilização da gamificação em processos de ensino e de aprendizagem, implica levar em consideração 6 (seis) itens fundamentais: "(1) os objetivos de aprendizagem; (2) as necessidades do aluno; (3) as modalidades do jogo; (4) a mecânica e as regras do jogo; (5) a avaliação das aprendizagens e (6) a experiência de jogo" (ROMERO, 2015, p. 67).

Decorre que a afirmação anterior, exige que proceda a análise de cada item relacionando-os com os elementos gamificados presentes no PDNM. Em vista disso, foi possível sintetizar que a análise do item 1 (um), expressa o resultado da mobilização cognitiva realizada pelos estudantes ao resolverem as questões com propostas pelo PDNM (Figura 2). 


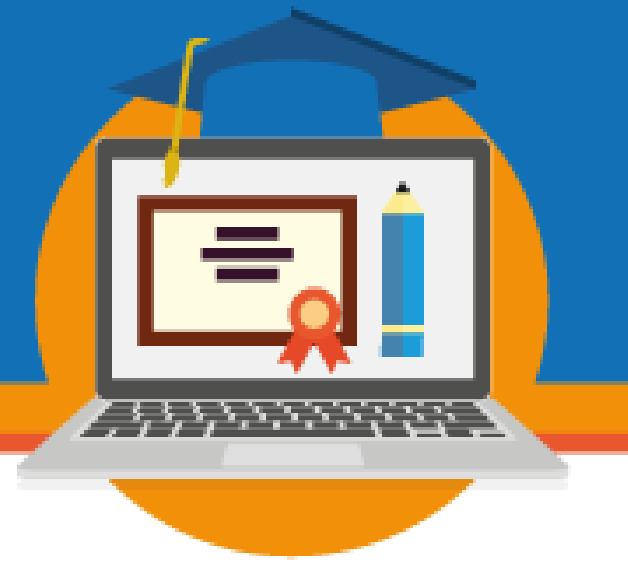

O componente, necessidades do aluno, remete à realização de simulados, cuja intencionalidade era detectar as lacunas de aprendizagem e a indicação de itinerários de estudos com vistas a resolver as deficiências por meio das tarefas programadas semanalmente (Figura 3) dos diversos conteúdos (item 3), ministrados durante o curso (Figura 4). Por outro lado, as mecânicas e as regras do jogo contidas no PDNM foram destacadas pelo desempenho dos alunos no processo de ação, apropriação, reflexão e resolução das atividades propostas (Figura 4).

O item avaliação foi contemplado no PDNM o tempo todo, mediante os instrumentos: simulados, questões bônus, tarefas semanais e realização de testes e provas envolvendo os conteúdos das áreas do conhecimento (Figuras 3 e 4). Aquelas ações realizadas pelos estudantes compõem a experiência do jogo e aprendizagem adquirida no processo de engajamento, imersão cognitiva e nas sínteses produzidas nas diversas atividades executadas (Figuras 4 e 5).

A gamificação, no processo de aprendizagem dos alunos do curso de Pedagogia da EaD, concebida como estratégia de estudos, proporcionou o contato, ação, teste, operação mental ao mobilizar os conhecimentos anteriores em confronto com os adquiridos no processo de estudos, produzindo sucessivas sínteses cognitivas na relação dialética do aluno com os conteúdos contidos no PDNM.

\section{Conclusão}

Ao encaminharmos as considerações finais, faz-se necessário retomar os objetivos propostos com a finalidade de evidenciar os resultados obtidos no processo de aquisição de conhecimento científico por parte dos estudantes do curso de licenciatura em Pedagogia de uma instituição de $\mathrm{EaD}$.

Em sentido lato, parece razoável destacar que a plataforma Studiare, forneceu suporte digital para a inserção de elementos e mecânicas da gamificação no PDNM, favorecendo ao estudante a imersão e a motivação no desenvolvimento de sucessivas atividades, mediadas pela leitura, estudos, avaliações e reconhecimentos pelo esforço dedicado. 


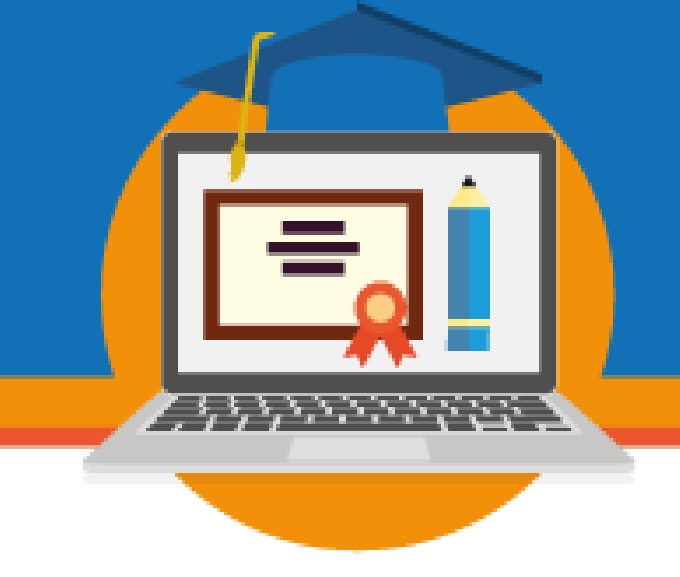

Desse modo, a gamificação presente no PDNM constituiu em uma estratégia de aprendizagem, e ao mesmo tempo uma alternativa didática para a $\mathrm{EaD}$, porque propiciou o engajamento e motivação, na promoção de aprendizagem dos conteúdos estudados nas diversas disciplinas do curso de graduação em Pedagogia.

A identificação das mecânicas de gamificação presentes no PDNM oportunizou ao aluno do curso de licenciatura em Pedagogia, a superação das lacunas de aprendizagem pelo processo de ação, apropriação e de reconstrução de novas representações acerca dos conhecimentos pedagógicos que subsidiaram a formação inicial de profissionais que poderão atuar em espaços escolares e não escolares, com a finalidade de mediar a educação e a formação científica dos indivíduos para viverem de forma autônoma na sociedade.

\section{Referências}

ALMEIDA, Maria Elizabeth Bianconcini de. Educação a distância na internet: abordagens e contribuições dos ambientes digitais de aprendizagem, 2003. Disponível em: $<$ http://www.scielo.br/pdf/ep/v29n2/a10v29n2.pdf $>$. Acesso em: 22 jan. 2018.

ALVES, Lynn. Games e educação: desvendando o labirinto da pesquisa. Revista da FAEEBA - Educação e Contemporaneidade, Salvador, BA, v. 22, n. 40, p. 177-186, jul./dez. 2013. Disponível

em: $<$ https://www.revistas.uneb.br/index.php/faeeba/article/view/761/534>. Acesso em: 23 jan. 2018.

. Games: desenvolvimento e pesquisa no Brasil. In: NASCIMENTO, Antonio Dias; HETKOWSKI, Tânia Maria (Org.). Educação e contemporaneidade: pesquisas científicas e tecnológicas. Salvador, BA: EDUFBA, 2009, p. 373-394. Disponível em: $<\underline{\text { http://books.scielo.org/id/jc8w4/17> }}$. Acesso em: 22 jan. 2018.

. Relações entre os jogos digitais e aprendizagem: delineando percurso.

Educação, Formação \& Tecnologias, PT, v.1, n. 2. 2008. Disponível em:

$<\underline{\text { http://eft.educom.pt/index.php/eft/article/view/58/38> }}$. Acesso em: 22 jan. 2018.

ALVES, Fabio Pereira; MACIEL, Cristiano. A gamificação na educação: um panorama do fenômeno em ambientes virtuais de aprendizagem. 2014. Disponível em:

$<$ https://www.researchgate.net/publication/269995356_A gamificacao_na educacao_um pan orama_do_fenomeno_em_ambientes_virtuais_de_aprendizagem $>$. Acesso em: 27 jan. 2018. 


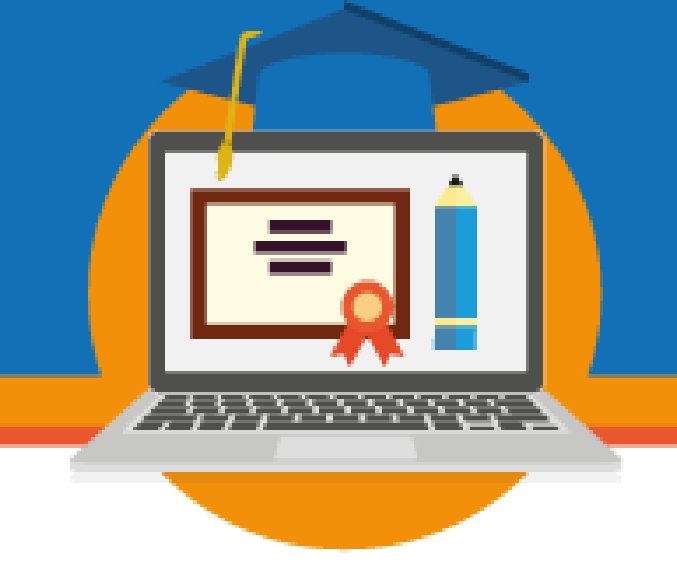

BEHAR, Patricia Alejandra. Modelos pedagógicos em educação a distância. 2009. Disponível em:

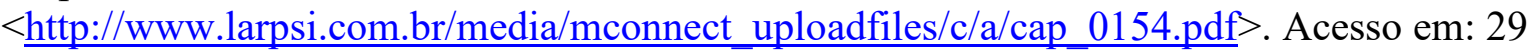
jan. 2018.

BEHAR, Patricia Alejandra; PASSERINO, Liliana; Bernardi, Maira. Modelos pedagógicos para Educação a Distância: pressupostos teóricos para a construção de objetos de aprendizagem. 2007. Disponível em:

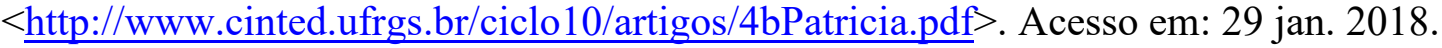

BORBA, Francisco da Silva. Dicionário Unesp do português contemporâneo. Curitiba, PR: Piá, 2011.

BRASIL. Decreto $n^{\circ}$ 9.057, de 25 de maio de 2017 que regulamenta o Art. 80 da Lei $n^{\circ}$ 9.394, de 20 de dezembro de 1996 que estabelece as diretrizes e bases da educação nacional.

Brasília, DF, Diário Oficial da União, de 26 de maio de 2017 e retificado em 30 de maio de 2017. Disponível em: $<$ http://www.planalto.gov.br/ccivil 03/_Ato2015-

2018/2017/Decreto/D9057.htm\#art24>. Acesso em: 27 jan. 2018.

FARDO, Marcelo Luis. A gamificação aplicada em ambientes de aprendizagem. RENOTE Revista Novas Tecnologias na Educação, Porto Alegre, RS, v.11, n. 1, jul. 2013. Disponível em: $<$ http://seer.ufrgs.br/index.php/renote/article/view/41629/26409>. Acesso em: 30 jan. 2018.

FRANÇA. Rômulo Martins; REATEGUI, Eliseo Berni; COLLARES, Darli. Mecânicas de games em um ambiente de aprendizagem baseado em questionamento. 2014. Disponível em:

$<$ http://www.sbgames.org/sbgames2014/files/papers/culture/full/Cult_Full_Mecanicas\%20de \%20Games.pdf > . Acesso em: 24 jan. 2018.

GAMES NA EDUCAÇÃO BRASILEIRA: solução de problemas ou ferramenta de aprendizado? UNIVERSIA, Brasil, BR, 21 mar. 2014. Disponível em:<

$<\underline{\text { http://noticias.universia.com.br/destaque/noticia/2014/03/21/1090136/games-na-educaco- }}$ brasileira-soluco-problemas-ou-ferramenta-aprendizado.html $>$. Acesso em: 29 jan. 2018.

GUTIERREZ, Felipe. Empresas usam jogos e representações de papéis para treinar os líderes. Folha de S. Paulo, SP, 31 maio 2015. Disponível em:

$<\underline{\text { http://classificados.folha.uol.com.br/empregos/2015/05/1635665-empresas-usam-jogos-e- }}$ representacao-de-papeis-para-treinar-os-lideres.shtml>. Acesso em: 29 jan. 2018.

KEEGAN, Desmond et al. 2092. E-learning: o papel dos sistemas de gestão da aprendizagem na Europa. Disponível em: $<\underline{\text { http: } / / w w w . p a n o r a m a e l e a r n i n g . p t / w p-~}$ 
content/uploads/2014/03/e Learning O-Papel-dos-Sistemas-de-gest\%C3\%A3o-daAprendizagem-na-Europa.pdf>. Acesso 30 jan. 2018.

MATTAR, João; NESTERIUK, Sérgio. Estratégias do design de games que podem ser incorporadas à educação distância. RIED. Revista Iberoamericana de Educação a Distância, Madrid-Espanha, v. 19, n. 2, 2016. Disponível

em: $<$ http://revistas.uned.es/index.php/ried/article/view/15680/14277> $>$. Acesso em: 25 jan. 2018 .

NOGUEIRA, Adriana da Silva; GALDINO, Anderson L. Games como agentes motivadores na educação. 2011. Disponível em: $<$ http://www.comunidadesvirtuais.pro.br/seminariojogos/files/mod_seminary_submission/trabalho_12/trabalho.pdf $>$. Acesso em: 22 jan. 2018.

PIMENTA, Fabrícia Faleiros; ALMEIDA, Bianca Starling Rosauro de. Gameficação de ambientes virtuais: tornando processo de ensino-aprendizagem mais atrativo. 2013. Disponível em: $<$ http://www.lantec.fe.unicamp.br/inova2013/images/trabalhos/artigos/2.pdf $>$. Acesso em: 23 jan. 2018.

PROGRAMA DESAFIO NOTA MÁXIMA. Orientações aos alunos. Universidade Norte do Paraná. Curitiba, PR. Kroton, 2017.

ROMERO, Margarida. Aprendizagem pelo jogo: da gamificação das aprendizagens aos jogos sérios. In: SANTOS, Gilberto Lacerda; LÉTTI, Mariana Marlière. GAMIFICAÇÃO: como estratégia educativa. Brasília, DF: Link Comunicação e Design, 2015.

SCLEMMER, Eliane. Games e gamificação: uma alternativa aos modelos de EaD. RIED. Revista Iberoamericana de Educação a Distância, Madrid-Espanha, v. 19, n. 2, 2016. Disponível em: $<$ http://revistas.uned.es/index.php/ried/article/view/15731/14278 $>$. Acesso em: 26 jan. 2018.

Gamificação em espaços de convivência híbridos e multimodais: design e cognição em discussão. Revista da FAEEBA - Educação e Contemporaneidade, Salvador, BA, v. 23, n. 42, p. 73-89, jul./dez. 2014. Disponível em:

$<$ https://www.revistas.uneb.br/index.php/faeeba/article/view/1029/709>. Acesso em: 26 jan. 2018.

SILVA, António Carlos Ribeiro da; MOITA, Filomena Maria Gonçalves da SILVA. Os games no contexto de currículo e aprendizagens colaborativas on-line. 2006. Disponível em:

$<$ http://www.filomenamoita.pro.br/pdf/osgames.pdf $>$. Acesso em: 22 jan. 2018. 


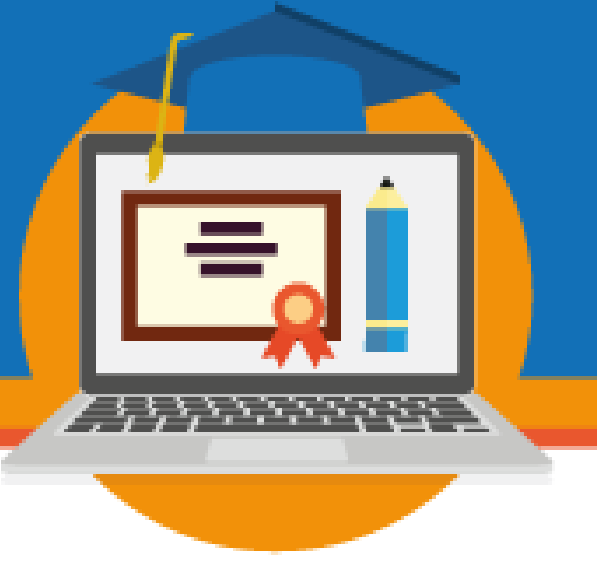

SILVA, Marco; CLARO, Tatiana. A docência online e a pedagogia da transmissão. Boletim Técnico do Senac: a revista de Educação Profissional, Rio de Janeiro, RJ, v. 33, n. 02, maio/ago, 2007. Disponível em: $<$ http://www.senac.br/conhecimento/boletim-tecnico-dosenac/edicoes-anteriores.aspx $>$. Acesso em: 28 jan. 2018.

TORRES, Velda; ALVES, Lynn. Professores e os jogos digitais: um olhar sobre as possibilidades pedagógicas destas mídias. Revista A Cor das Letras, Feira de Santana, BA, v. 14, n. 1, 2013. Disponível em:

$<$ http://periodicos.uefs.br/index.php/acordasletras/article/view/1456/pdf $>$. Acesso em: 23 jan. 2018.

VIDOR, George. O mercado de 'games' no mundo fatura mais que cinema e música, somados. O Globo, Rio de Janeiro, RJ, 25 maio 2015. Disponível em:

$<$ https://oglobo.globo.com/economia/o-mercado-de-games-no-mundo-fatura-mais-quecinema-musica-somados-16251427>. Acesso em: 29 jan. 2018. 